\title{
EDITORIAL
}

\section{Campaign to revitalise academic medicine kicks off}

\author{
We need a deep and broad international debate to begin
}

$\mathrm{T}$

The $B M J$ and a range of partners, including other journals published by the BMJ Publishing Group, the Lancet, Canadian Medical Association Journal, Dutch Journal of Medicine, Medical Journal of Australia, Croatian Medical Journal, the Academy of Medical Sciences, and many others have initiated a project to bring people together to debate whether the existing structure of academic medicine is still fundamentally sound and, if not, to propose alternatives to it. ${ }^{1}$ I have taken on the challenge of coordinating this project, and I invite readers to join me in this enterprise.

To achieve the project's broad goals (box 1) we begin from the position that "more of the same" is not enough. We need to be free to propose radical changes to the fundamental nature of academic medicine (is the balance between bench and applied research all wrong?); its name (should it become "academic health care" or should we drop "academic"?); its home base (are hospitals the wrong place to train doctors?); its relation to service (why are they so often far apart?); its methods of training and certification (should medical education be lecture based and far shorter?); and its responsibilities (should it be held accountable for inequities in health care at the global level?).

Our approach will be inclusive and is designed to ensure a broad input of opinions. Rather than allowing the process to be taken over by a few experts with vested interests, we will build consensus by inviting a range of global stakeholders to contribute their views. We are especially interested in the views of the "customers" of academic medicine - patients, politicians, the public. Anyone can

\section{Box 1. Goals of the project}

Development of strategy on the following issues:

- How should academic medicine look in the 21 st century

- How can we increase the impact of academic medicine on the rest of medicine and on health and health care

- How should academic medicine be positioned internationally within medicine and also in the wider intellectual arena

- How can recruitment to and job satisfaction of those working in academic medicine be increased

\footnotetext{
Box 2. Four advisory groups

- Perspectives forum — patients, health professionals, government representatives, and medical unions

- Ad hoc consultants - providing systematic reviews and other factual summaries about the efficacy of different educational, organisational, and administrative approaches, and trends in human resources in academic medicine

- Communications consortium — disseminating surveys, drafts, and reports to everybody who is joined up to the campaign or may want to give input

- International advisory panels - deans and chairs whose support could help establish funding, profile, and implementation; also used as an ongoing sounding board
}

REPORDUCED FOR JHPN READERS contribute their views right now, as a rapid response to this article at bmj.com In addition, our project web page is under development (www.bmj.com/academicmedicine), and this will contain regular updates, news, and collected resources.

The proposed structure is as follows. The pivotal group will be an international working party whose composition will include knowledge and competency across the dimensions of global health and basic to applied healthcare research, representing the range of constituents (medical students, postgraduates, junior faculty, established academics - especially women). Supported by four advisory groups (box 2) and made up of approximately eight individuals, the working party will begin by answering four questions. Firstly, what are the roles of academic medicine?

Secondly, how well is academic medicine carrying out these roles? Responses to the earlier $B M J$ editorial launching this initiative have already nominated a wide array of (but no clear consensus about) perceived failures, including failing to serve the public good, lack of a global perspective, an unnecessary dichotomy between education and research, various shortcomings in medical education, and inadequate numbers of and career paths for well trained medical academics. ${ }^{2}$

Thirdly, why is academic medicine failing to fulfil its roles? Reasons might include inadequate leadership, a failure to translate discoveries into benefits for patients, inappropriate incentives to take up or maintain an academic career (especially among women), deficient mentoring for aspiring academics, lack of appreciation of the benefits of academic medicine by elected represetatives, and poor integration with other health services. Many of the reasons will be economic but we need to examine ethical and moral explanations as well.

Finally, for each failure, what ought to be done about it? Given economic constraints in countries with high and low income, special attention will go to strategies that call for no additional funding. We will, however, welcome strategies that call for the reallocation of funding. We welcome strategies for how academic medicine can contribute to national and global health. These strategies will be combined and formulated into concrete proposals for action.

We need your help. To nominate a member of the working party, join a group, or register your views, send a rapid response to bmj.com or contact our project manager, Jocalyn Clark, at jclark@bmj.com

Peter Tugwell professor

Department of Medicine, University of Ottawa, Institute of Population Health, Ottawa, ON, Canada K1N 6N5

(ptugwell@uottawa.ca)

1. Academic medicine: resuscitation in progress. CMAJ 2004;170:309.

2. Clark J, Smith R. BMJ publishing group to launch an international campaign to promote academic medicine. BMJ 2003;327:1001-2.

This editorial was originally published in the $B M J$ on 13 march 2004 (BMJ 2004:328:597). It was also published simultaneously in the Lancet. 